\title{
Where to Find? A Report for Some Terrestrial Fungal Isolates, and Selected Applications Using Fungal Secondary Metabolites
}

\author{
Waill A Elkhateeb* and Ghoson M Daba \\ Department of Chemistry of Microbial Natural Products, National Research Center, Egypt
}

Received: May 04, 2018; Published: May 15, 2018

*Corresponding author: Waill A. Elkhateeb, Department of Chemistry of Microbial Natural Products, National Research Center, Tahrir Street, 12311, Dokki, Giza, Egypt

Abstract

Biodiversity of mycobiota is getting more attention, since fungi and their metabolites represent the future alternatives of many currently used chemical compounds. In this review, the fungal mycobiota associated with leaves of some plants were discussed comparing the literatures focusing on some economically important plants such as wheat, sugarcane, and some medical plants. Furthermore, the role of some fungi as promising small factories that could be used for industrial applications such as myco-diesel oil production, and agricultural applications such as plant growth promoters

Keywords: Fungal Biodiversity; Isolation; Identification; Phylloplane fungi; Mycobiota; Medicinal Plant; Myco-Diesel

\section{Introduction}

Biodiversity describes the variability among living organisms within a given ecosystem, and it is often used to measure the health of biological systems. Documenting and describing fungal diversity is an extremely difficult mission that requires years of experience due to their ability to appear in various morphologies from a single individual, and their confusing similarity in appearance to non closley- related taxa [1]. There are many methods used from decades to analyze fungal biodiversity. The classical methods rely on direct observation of fungi. These methods are cheaper and need no specific equipment in comparison with molecular based methods which rely on sampling fungal DNA. Classical methods are commonly used specially in developing countries, which usually cannot afford applying molecular methods. Classical methods are hence accompanied by doing many investigations, and record fungi over a specific area and /or amount of substrate [2,3]. Putting also in consideration ecological variables, such as $\mathrm{pH}$, soil nutrients composition, age of the plant, time of the year, and some other weather-related variables [4].

Fungi are ubiquitous, and new species can be isolated even from the most well studied areas [5]. The word phylloplane point to the surface of plant leaves which represents a complex terrestrial habitat and so studying phylloplane mycobiota is concerned with the fungal flora growing on the surface of plant leaves [3]. Many studies focused on investigating phylloplane fungal flora of several plants growing or cultivated in Egypt and other parts of the world
[6-13]. There are two groups of phylloplane fungi: residents and casuals. Residents multiply on the surface of healthy leaves without harming the host plant or affecting it. While, casuals though existing on the surface of the leaf, they cannot grow on it. [14,15]. Studying biodiversity of mycobiota is very important for identifying and documenting changes and similarities between species. Moreover, various novel natural compounds can be isolated and identified from such mycobiota with promising potential biological, medical and industrial applications [16]. In this review, phylloplane mycobiota from some economically important plants and some medicinal plants were described. Moreover, using some fungal strains as small factories to produce valuable compounds involved in many applications was discussed.

\section{Isolation of Phylloplane Mycobiota}

A common method for isolation of phylloplane mycobiota, the agar plate method, was described by Elkhateeb [4], include washing leaves of the plant several times with distilled water, and dry them between sterile filter paper, followed by cutting the leaf into equal segments (about $1 \mathrm{~cm}$ each). Five segments were placed in each plate on the surface of the agar medium supplemented with appropriate antibacterial. Then, the plates were incubated at $28^{\circ} \mathrm{C} \pm$ 1 for 7-10 days, and the developing fungi were counted, identified, and calculated as colony forming unit "cfu" per 100 segments of fresh leaves. 
Another commonly used method is moist chamber plate's method [17], which doesn't require using any type of medium for the growth of Phylloplane fungi. In this method the leaf segments of $1 \mathrm{Cm}$ square, both sterile an unsterile were placed separately on the moist chamber plates using a sterile forceps and pressed genteelly, followed by incubation at $25 \pm 3^{\circ} \mathrm{C}$ in the incubation chamber for 7 to 21 days. But starting from the fourth day monitoring plates is very important in order to check the growth of fungi. The fungi on moist chamber were then counted.

\section{Mycobiota from Economically Important Plants}

Wheat is one of the most economically important plants worldwide. Many fungal genera were listed to be isolated from wheat. Abdel-Hafez [18] reported that the most common phylloplane genera isolated from wheat leaves cultivated in Saudi Arabia were Cladosporium, Aspergillus, and Alternaria, which came in accordance with Abdel-Hafez et al. [19] who reported the same genera Alternaria, Aspergillus, and Cladosporium, but he also added Cochliobolus, Gibberella, Nectria, and Penicillium. Solated to the list of common mycobiota isolated from wheat fields in El-Kharga Oasis, Western desert, Egypt. On the other hand, Mazen et al. [20] nominated the most common species isolated from phylloplane of wheat plants as Aspergillus niger, Penicillium corylophilum and Alternaria alternata.

Mycobiota biodiversity isolated from wheat were found to differ according to the plant part they were isolated from. Larran et al. [21] reported Rhodotorula rubra, Alternaria alternata, Cladosporium herbarum and Epicoccum nigrum as the predominant species isolated from wheat (Triticum aestivum L.). Whereas Larran et al. [22] recorded Alternaria, Penicillium, Stemphylium, Fusarium, Aspergillus, Ulocladium, Epicoccum, Acremonium and Pythium sp. to be the species highly colonizing in crown tissues, and Alternaria, Stemphilum, Penicllium, Epicoccum, Ulocladium, Nigrospora, Torula, Septonema, Aspergillus and Phaeoseptoria spp. as species predominantly colonizing leaves, while Alternaria, Stemphilum, Penicillium, Cladosporum, Ulocladium, Epicoccum, Fusarium, Popularia, Nigrospora and Trichoderma spp. as genera commonly isolated from ears of wheat.

Surveying mycobiota associated with sugarcane revealed that Aspergillus flavus, A. niger, Cochliobolus spicifer, Fusarium oxysporum, Gibberella fujikuroi, Nectria haematococca and Penicillium chrysogenum were the most common species $[23,24]$ studied the fungal biota of leaf surface of banana and recorded the most common genera as Alternaria, Aspergillus, Chaetomium, Cladosporium, Cochliobolus, Curvularia, Gibberella, Memnoniella, Mycosphaerella, Setosphaeria and Stachybotrys. Surveying mycobiota on grapevine plantations in Sahel-Saleem City, Assuit Governorate, Egypt, predominated Aspergillus niger and A. aculeatus, Penicillium count came second after Fusarium. Penicillium. Purpurogenum and Fusarium oxysporum were the common species [25].

\section{Phylloplane Mycobiota from Medicinal Plant}

Prabakaran et al. [15] Survey on the occurrence of phylloplane fungi on leaves surface of three important medicinal plants such as Ocimum sanctum (holy basil), Phyllanthus amarus (sleeping plant), and Azadirachta indica (neem tree), revealed predominance of Aspergillus flavus, Penicillium expansum, Fusarium semitectum, Fusarium oxysporum in the phylloplane of Ocimum sanctum. On the other hand, Scopulariopsis sp. was isolated from the phylloplane of Phyllanthus amarus, whereas Penicillium janthinellum, Aspergillus fumiculosis, Aspergillus sp., Curvularia lunata and Fusarium moniliforme were isolated from the phylloplane of Azadirachta indica. Nayak [17] studied mycobiota isolated from Tinospora cordifolia (heart-leaved moonseed), and nominated the species Alternaria alternata, Aspergillus niger, Cladosporium herbarum, Penicillium chrysogenum as dominant fungal taxa among the recorded species.

Nayak [26] described mycobiota isolated from leaves of Solanum nigrum using two different techniques, agar plate method and moist chamber plates method. He reported isolation of 16 fungi under 10 genera from both used methods. In agar plate technique, Penicillium digitatum, Aspergillus awamori, Alternaria were isolated but, by using moist chamber technique, Torula herbarum, Trichoderma harzianum and Aspergillus flavus were isolated from the leaf samples. Alternaria sp., Cladosporium herbarum, Aspergillus awamori, A. flavipes, A. Niger, Monascus sp, Penicillium citrinum, P. digitatum, Torula herbarum and Trichoderma harzianum were identified as phylloplane fungi.

\section{Fungal Secondary Metabolites with Beneficial Properties}

It is already known that fungi secretes a wide range of secondary metabolites which represent an excellent source of compounds with promising applications for industry, medicine, and agricultural fields. For example, Epicoccum Sp. is known to secrete many secondary metabolites such as epicorazines which has an antibacterial activity $[27,28]$. Trichoderma Sp. is widely used as biofertilizers and biocontrol agents in agriculture due to its secreted secondary metabolites that exert different biological activities towards plants and other microbes [29]. T. harzianum produces an important metabolite, harzianic acid (HA) which promotes plant growth [30]. Another metabolite was isolated from the culture filtrate of a T. harzianum strain a, termed isoharzianic acid (iso-HA), which has antifungal activities In vitro aganist Sclerotinia sclerotiorum and Rhizoctonia solani. [30-39].

\section{Oil Production}

The current energy crisis has highlighted the importance of searching for potent alternative oils and for synthesis of microbial lipids, which represent the raw material for biodiesel production [40]. Many fungi can accumulate high level of lipids and grow as pellets that can easily be harvest from cell broth [41]. One of the most potent fungus in oil production is Mucor circinelloides. Pellet formation in submerged fungal cultivation of M. circinelloides depends strongly on adjusting $\mathrm{pH}$ during cell growth [42]. Many agricultural wastes such as Sugar beet pulp (SBP) can be used as substrate for production of fungal oil from Mucor circinelloides and Aspergillus oryzae, which is an economical way to offer an alternative to oil to be used as an energy source. Another fungus, Cunninghamella japonica, was reported as a promising lipid producer [43-45]. 


\section{Conclusion}

As described in this review, even the well-studied area can yield new fungal isolates with metabolites to be investigated. Further studies on the isolation and identification of fungi as well as investigating and prospecting their secondary metabolites for biotechnological uses or biologically important application, represent a critical need nowadays. Fungi isolated from medicinal plants usually exerts novel and important biological activities. Documenting the species composition of fungal mycobiota existing over the world and comparing this information may contribute in understanding relation between presence of such genera and many other factors.

\section{References}

1. Yahr R, Conrad L, Bryn T (2016) Scaling up discovery of hidden diversity in fungi: impacts of barcoding approaches. Phil Trans R Soc 371: 1702.

2. Mueller GM, Schmit JP, Huhndorf SM, O’Dell TE, Lodge DJ, et al. (2004) Measuring and monitoring diversity of terrestrial and Lignicolous macrofungi: recommended protocols for sampling macrofungi. In Biodiversity of Fungi: Inventory and Monitoring Methods, Mueller GM Bills GF, Foster MS, (Eds.). Academic Press, New York, USA, pp: 123-168.

3. Schmit, Lodge (2004) Classical Methods and Modern Analysis for Studying Fungal Diversity. Mycology Series 23: 193.

4. Elkhateeb WA (2005) Some mycological, phytopathological and physiological studies on mycobiota of selected newly reclaimed soils in Assiut governorate, Egypt. Master thesis, faculty of scenic, Assiut University.

5. Straatsma G, Ayer F, Egli S (2001) Species richness, abundance, and phenology of fungal fruit bodies over 21 years in a Swiss forest plot. Mycol Res 105: 515-524.

6. Xiang S, Liang Dong G (2012) Endophytic fungal diversity: review of traditional and molecular techniques 3(1): 65-76.

7. Liu L, Liu S, Jiang L, Chen X, Guo L, et al. (2008) Chloropupukeananin, the first chlorinated pupukeanane derivative and its precursors from Pestalotiopsis fici. Org Lett 10: 1397-1400.

8. Liu L, Li Y, Liu S, Zheng Z, Chen X, et al. (2009) Chloropestolide A, an antitumor metabolite with an unprecedented spiroketal skeleton from Pestalotiopsis fici. Org Lett 11: 2836-2839.

9. Liu L, Niu S, Lu X, Chen X, Zhang H, et al. (2010) Unique metabolites of Pestalotiopsis fici suggest a biosynthetic hypothesis involving a DielsAlder reaction and then mechanistic diversification. Chem Commun 46: 460-462.

10. Liu L, Bruhn T, Guo L, Götz D, Brun B, et al. (2011) Chloropupukeanolides C-E, cytotoxic pupukeanane chlorides with a spiroketal skeleton from Pestalotiopsis fici. Chem Eur J 17: 2604-2613.

11. Aly A, Debbab A, Kjer J, Proksch P (2010) Fungal endophytes from higher plants: a prolific source of phytochemicals and other bioactive natural products. Fungal Divers 41: 1-16.

12. Li J, Li L, Si Y, Jiang X, Guo L, et al. (2011) Virgatolides AC, benzannulated spiroketals from the plant endophytic fungus Pestalotiopsis virgatula. Org Lett 13: 2670-2673.

13. Tejesvi M, Kajula M, Mattil AS, Pirttilä A (2011) Bioactivity and genetic diversity of endophytic fungi in Rhododendron tomentosum Harmaja. Fungal Divers 47: 97-107.

14. Nostro A, Germano MP, Angelo V, Marino A, Cannatelli MA (2000) Extraction methods and bioautography for evaluation of medicinal plant antimicrobial activity. Lett Appl Microbiol 30(5): 379.

15. Prabakaran M, Merinal S, Panneerselvam A (2011) Investigation of phylloplane mycoflora from some medicinal plants. European Journal of Experimental Biology 1(2): 219-225.
16. Elkhateeb WA, Zohri A, Mazen M, Hashem M, Daba G (2016) Investigation of diversity of endophytic, phylloplane and phyllosphere mycobiota isolated from different cultivated plants in new reclaimed soil, Upper Egypt with potential biological applications. Int J MediPharm Res 2(1): 23-31.

17. Nayak BK (2015a) Biodiversity of phylloplane and endophytic fungi studied on the medicinal plant; Tinospora cordifolia. International Journal of Chemical Concepts 1(3): 109-113.

18. Abdel Hafez SII (1981) Phyllosphere and phylloplane fungi of wheat cultivated in Saudi Arabia. Mycopathologia 75(1): 33-38.

19. Abdel Hafez SII, Moharram AM, Abdel Sater MA (2000) Monthly variations in the mycobiota of wheat fields in El-Kharga Oasis, Western desorts, Egypt. Bull Fac Sci Assiut University 29 (2-D): 195-211.

20. Mazen MB, Abdel Hafez SI, Shaban GM (1985) Seasonal fluctuations of phyllosphere and phylloplane fungi of Egyptian wheat. Acta Mycologica 21(1): 109-116.

21. Larran S, Perello' A, Simo'n M, Moreno V (2002) Isolation and analysis of endophytic microorganisms in wheat (Triticum aestivum L.) leaves. World Journal of Microbiology \& Biotechnology 18: 683-686.

22. Larran S, Perelló A, Simón M, Moreno M (2007) The endophytic fungi from wheat (Triticum aestivum L.). World J Microbiol Biotechnol 23: 565-572.

23. Abdel Hafez SI, El Said AH, Gherabawy YA (1995) Mycoflora of leaf surface stem, bagasse and juice of adult sugarcane (Saccharum officinarum L.) plant and cellulolytic ability in Egypt. Bull Fac Sci Assiut Univ 24: 113130.

24. El Said AH (2001) Phyllosphere and Phylloplane Fungi of Banana Cultivated in Upper Egypt and their Cellulolytic Ability. Mycobiology 29(4): 210-217.

25. Abdel Sater MA, Moubasher AH, Soliman ZS (2016) Diversity of filamentous and yeast fungi in soil of citrus and grapevine plantations in the Assiut region Egypt. Czech mycology 68(2): 183-214.

26. Nayak BK (2015b) Enumeration of phylloplane and endophytic fungi from medicinal plant. Solanum nigrum by two different techniques 1(3): 103-108.

27. Baute MA, Deffieux G, Baute R, Neveu A (1978) New antibiotics from the fungus Epicoccum nigrum. I. Fermentation, isolation and antibacterial properties. Journal of Antibiotics 31: 1099-1101.

28. Ikawa M, Mcgrattan CJ, Burge WR, Iannitelli RC, Uebel JJ, et al. (1978) Epirodin, a polyene antibiotic from mold Epicoccum nigrum. Journal of Antibiotics 31: 159-160.

29. Sawa R, Mori Y, Iinuma $H$, Naganawa $H$, Hamada $M$, Yoshida $S$, et al. (1994) Harzianic acid, a new antimicrobial antibiotic from a fungus. J Antibiot 47: 731-732.

30. Vinale F, Flematti G, Sivasithamparam K, Lorito M, Marra R, et al. (2009): Harzianic acid, an antifungal and plant growth promoting metabolite from Trichoderma harzianum. J Nat Prod 72: 2032-2035.

31. Abdel hafez SII, Abo Elyousr KA, Ismail R (2015) Leaf surface and endophytic fungi associated with onion leaves and their antagonistic activity against Alternaria porri. czech mycology 67(1): 1-22.

32. Michal K, Viera B, Emília Ga, Zuzana O, Daniela H (2013) Secondary metabolite production of Epicoccum sp. isolated from lignite. Acta Chimica Slovaca 6(1): 42-48.

33. Guo H, Sun B, Gao H, Chen X, Liu S, et al. (2009) Diketopiperazines from the Cordyceps-colonizing fungus Epicoccum nigrum. Journal of natural products 72(12): 2115-2119.

34. Wang JM, Ding GZ, Fang L, Dai JG, Yu SS, etal. (2010) Thiodiketopiperazines produced by the endophytic fungus Epicoccum nigrum. Journal of natural products 73(7): 1240-1249. 
35. Vinale F, Gelsomina M, Marco N, Pierluigi M, Alessandro P, et al. (2014): A Novel Fungal Metabolite with Beneficial Properties for Agricultural Applications. Molecules 19: 9760-9772.

36. Abo elyousr KA, Abdel Hafez SI, Abdel rahim IR (2014) Isolation of Trichoderma and evaluation of their antagonistic potential against Alternaria porri. Journal of Phytopathology 162(9): 567-574.

37. Dias DA, Urban S, Roessner UA (2012) Historical Overview of Natural Products in Drug Discovery. Metabolites 2: 303-336.

38. Vinale F, Sivasithamparam K, Ghisalberti EL, Marra R, Barbetti MJ, et al. (2008) A novel role for Trichoderma secondary metabolites in the interactions with plants. Physiol Mol Plant Pathol 72: 80-86.

39. Reino JL, Guerrero RF, Hernández Galán R, Collado IG (2008) Secondary metabolites from species of the biocontrol agent Trichoderma. Phytochem Rev 7: 89-123.

40. Angerbauer C, Siebenhofer M, Mittelbach M, Guebitz G (2008) Conversion of sewage sludge into lipids by Lipomyces starkeyi for biodiesel production. Bioresour Technol 99: 3051-3056.

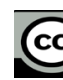

This work is licensed under Creative Commons Attribution 4.0 License

Submission Link: https://biomedres.us/submit-manuscript.php
41. Liao W, Liu Y, Chen S (2007) Studying pellet formation of a filamentous fungus Rhizopus oryzae to enhance organic acid production. Appl Biochem Biotechnol 137: 689-701.

42. Chunjie X, Jianguo Z, Weidong Z, Bo H (2011) A new cultivation method for microbial oil production: cell pelletization and lipid accumulation by Mucor circinelloides. Biotechnology for Biofuels 4:15.

43. Sergeeva YE, Galanina LA, Andrianova DA, Feofilova EP (2008) Lipids of Filamentous Fungi as a Material for Producing Biodiesel Fuel. Applied Biochemistry and Microbiology 44(5): 523-527.

44. Venkata S, S Venkata M (2014) Lipid accumulation for biodiesel production by oleaginous fungus Aspergillus awamori Influence of critical factors. Fuel 116: 509-515.

45. Duygu O, Ezgi B, Canan C, Dilan E, Deniz, K, van Leeuwen (2015) Fungal Oil Production from Oleaginous Fungi Mucor circinelloides and Aspergillus oryzae Cultivated on Sugar Beet Pulp. APJES 734-741.

\begin{tabular}{ll} 
BIOMEDICAL & Assets of Publishing with us \\
RESEARCHES & - Global archiving of articles \\
& - Immediate, unrestricted online access \\
& - Rigorous Peer Review Process \\
\hline
\end{tabular}

